\title{
ELS PERSONATGES FEMENINS FATALS DEL GINEMA ESPANYOL DELS ORÍGENS
}

\author{
Mireia Canals Botines
}

Universitat de Vic

Sovint, quan ens referim als personatges femenins fatals del cinema espanyol, ens vénen a la ment aquells personatges internacionals que no s'assemblen gaire als d'aqui. No obstant, el nostre cinema, des dels seus inicis, ens ofereix l'oportunitat de conèixer múltiples varietats del personatge de la dona fatal, en diverses modalitats i gèneres. L'objectiu d'aquest article és el de suggerir alguns d'aquests personatges dins d'algunes trames cinematogràfiques mudes, i mostrar diferents tipus de dones fatals, alhora que veure'n característiques comunes, tant del personatge com de la fesomia, els títols i el cartellisme.

\section{EL CINEMA DELS ORÍGENS}

El cinema dels orígens comença amb vistes documentals, notícies filmades. A la dècada dels deu s'implanten els llargmetratges i la importació de pel.lícules dels països nòrdics. En aquestes pel.lícules, els productors s'adonen de la gran importància que tenen els actors per tal que el públic els conegui i pugui identificar-se amb ells amb major facilitat. Aquest és un fenomen que no triga a consolidar-se arreu del món, amb un plantell d'actrius europees que marquen una trajectòria cinematogràfica de manera iniciàtica femenina molt sòlida i perfilen el personatge de la dona fatal des d'una perspectiva més senzilla, que completaran les estrelles de Hollywood de forma més sofisticada en una segona fase d'evolució. Segons afirma Gubern, i fruit de la literatura europea, el personatge més productiu del cinema mut va ser "I'arquetip de la vampiressa", que no va ser res més que el traspàs al cinema del personatge engendrat per la literatura romàntica'. D'altra banda, el personatge de la dona malvada troba les seves arrels en la literatura de tots els temps però trobem personatges que, si bé no són grans personatges per al públic del país on van ser creats² $^{2}$ sí que enceten una tradició caracterial determinada en el país on situen aquest personatge femení i d'on el

$1 \quad$ Parlem del personatge del vampir i dels seus antecedents literaris, i paral.lelament parlem del personatge de la dona malvada. Com a conseqüència, s'esdevé la dona fatal, una síntesi de les característiques de dues tipologies de personatges que evolucionen cap a la dona fatal, que encaixa de manera més adient en el cinema.

2 Com és el cas del personatge de Carmen, de la novel.la Carmen de Prosper Mérimée (1845). 
fan originari. Aquests personatges, que es plasmen a la pantalla, tenen com a representants diverses actrius nòrdiques i algunes dives italianes. La fusió d'aquests dos tipus de dona i de personatge porten el cinema a desenvolupar el personatge de la dona fatal. En el cinema mut, la varietat d'actrius que representen aquest tipus de personatges és àmplia i diferenciada. Amb això, no ens ha de sorprendre que aquestes dones fatals tan coquetes, sofisticades i cíniques tinguessin mala premsa. Uns àngels malignes d'aquesta mena, vinguts a la terra per temptar els homes, "poden inspirar el desig però no l'estima" (Azzopardi, 1997:14). I arran d'aquest fet podem deduir que la fatalitat que les denomina va dirigida a la seva presa, qualsevol home que es deixi endur pel desig. Pel que fa referència al tipus "dona fatal", trobem al cinema, i en relació a aquest, d'altres tipus femenins no menys significatius: "la jove innocent", "la mare abnegada" o "I'heroïna", entre d'altres, que sovint apareixen en els relats com a contrast amb el tipus "dona fatal" i serveixen a la trama per donar més rellevància al personatge maligne. Sovint, l'oposició del bé i el mal és el pretext per al desenvolupament del film, on trobem al personatge masculí entremig, víctima de l'enfrontament.

\section{EL CAS ESPANYOL}

D'entre el plantell d'actrius del cinema mut espanyol que representen els antecedents del personatge de la dona fatal, podem destacar-ne tres que, a l'igual que va passar en el cinema d'arreu, van viure vides dramàtiques i van oferir una imatge desafiant dins del context social de l'època. Parlem de Rosario Pino, Raquel Meller i Margarita Xirgu. Rosario Pino va començar en el teatre i s'hi va dedicar majoritàriament, però va interpretar alguns personatges en el cinema, majoritàriament dramàtics. Entre d'altres, l'any 1928 la va dirigir Benito Perojo a La Condesa María (González; Cánovas, 1993:45-46), una història amb una dona fatal, que en aquesta versió sembla ser la neboda de la Condesa, que pretén obtenir amb tota premura la fortuna de la seva tia $^{3}$. Raquel Meller ${ }^{4}$ és coneguda arreu com la diva cupletista del paral.lel dels anys vint. En un recull de El Correo Catalán ${ }^{5}$, podem llegir sobre l'actriu i cupletista: "En sus actuaciones [la artista] combinaba perfectamente lo que eran los elementos básicos del cuplé: su belleza, la insinuación y sus evidentes cualidades interpretativas". La importància d'aquesta actriu rau en el fet que representa el tipus de dona misteriosa i seductora, tant en l'ofici de cupletista que té inicialment com en el d'actriu que assoleix més endevant, convertint-se en una estrella i un mite del món artístic. La primera pel.lícula que interpreta és Los arlequines de seda y oro, també anomenada "La gitana blanca". També és la primera actriu espanyola que interpreta la Carmen ${ }^{6}$ de Mérimée, i en la seva filmografia trobem títols que ens fan intuir el tipus de personatges que interpreta al llarg de la seva carrera cinematogràfica: La venenosa ${ }^{7}$ La gitana blanca ${ }^{8}$, entre d'altres. Sobre l'obra de Mérimée, trobem, almenys, tres adaptacions

3 Parlem de versió, en tant que hem pogut accedir a d'altres versions, i hem vist una posada en escena diferent, on l'argument varia i es crea un traspàs de dona fatal, d'un personatge a un altre.

4 De nom Francisca Marqués López i aragonesa d'origen.

5 Dins d'un especial del diumenge d'El Correo Catalán, titulat: “Un siglo de Catalunya. En los 100 años de EL CORREO CATALÁN. 22. Diversiones populares y espectáculos. Nace el cine", pp. 10 i 11. Contingut dins d'un recull de premsa del realitzador Fructuós Gelabert, a la Biblioteca de Cinema de la Generalitat de Catalunya.

6 França, Jacques Feyder, 1928.

7 França, Roger Lion, 1928, a partir de la novel.la de José María Carretero i on interpreta Miss Liana.

8 Espanya, Ricardo de Baños, 1919, on interpreta la gitanilla blanca.

Quaderns, 5 (2010), pp. 25-31 
cinematogràfiques espanyoles en els primers temps: Carmen, la hija del bandido (R. de Baños/ A. Marro, 1909), Carmen (A. Turchi, 1913) i La otra Carmen (J. de Togres, 1915). D'entre les tres actrius esmentades anteriorment, la que va tenir una carrera cinematogràfica més extensa va ser Margarita Xirgu. D'entre els seus papers més destacats on podem trobar traces del personatge de la dona fatal, esmentem El nocturno de Chopin', on la muller d'un ric marquès és malentesa per aquest en pensar que té un amant, per la qual cosa la repudia i li prohibeix veure la seva filla de per vida. Dins d'un argument força masclista i amb poca base dramàtica, les vivències de la marquesa, ara la mundana Violeta, la converteixen en dona fatal, donat que es converteix en l'amant — coqueta i de mala vida — d'un aristòcrata. Només l'amor per la seva filla la fa retornar a la llar familiar on, en veure la filla malalta, plena de culpabilitat, intenta suïcidar-se. Tot i ser de gran èxit entre el públic, la Xirgu només interpretarà per al cinema tres títols més, dins d'una sèrie de cinc pactats amb la productora Bacinógrafo:, La reina joven, Alma torturada/Almas torturadas i El beso de la muerte, ambdues produccions de Magí Murià, la primera de l'any 1915 i la segona i la tercera del 1916 (Aguilar i Genover, 1996:663). En el primer, trobem de nou un argument on l'equivocació d'un marit gelós porta la muller a passar per una sèrie d'incidents desagradables. Aquesta vegada, però, el marit és el culpable del drama. Aquest se suïcida i deixa que la muller refaci la seva vida amb un home honest. L'equívoc, però, situa el personatge en una situació de "falsa dona fatal", de pretesa dona fatal, tot i no ser-ho dins de la veritat argumental. L'actriu només reemprèn l'activitat en el cinema l'any 1938, de la mà d'Edmundo Guilbourg, a Bodas de sangre (Argentina, 1938) en el paper protagonista de l'obra de García Lorca.

D'altra banda, podem començar a parlar de la interpretació del personatge per part d'altres estrelles del cinema mut espanyol. Ja l'any 1910, Ricardo de Baños i Alberto Marro mostren un personatge femení que es comença a acostar al personatge que serà la dona fatal en el cinema. És el cas de la mora Aldara a Locura de amor, R. Baños i A. Marro, 1910, fruit de I'adaptació lliure de l'original teatral La locura de amor, 1855, de Manuel Tamayo i Baus. (Ruiz, 2000: 94). En el film, la jove Aldara és presentada com l'amant del capità Álvaro de Estúñiga, que retorna d'Itàlia malferit. Aldara serà motiu desencadenant de les passions del rei Felip i, com a conseqüència, causa de les distorsions en la relació entre aquest i la reina Isabel la Catòlica. De fet, en aquest cas, no podem parlar de la plasmació de la dona fatal, donat que el personatge d'Aldara no planeja ni manipula ni té una finalitat concreta. No obstant això, se'ns mostra com a amant i seductora, unes característiques pròpies del personatge de la dona fatal i que ens serveixen com a antecedent del tipus. Alhora, Aldara és una mora infidel, cosa que fa que es potenciïn les característiques negatives que tot just hem esmentat. L'actriu que interpreta el personatge és Emilia de la Mata. En un altre sentit, l'any 1911 Juan María Codina realitza Amor que mata ${ }^{10}$, un drama passional. Val a dir que Palmira González data la producció del mes de gener del 1909 (González, 1987: 411). En aquest cas hi ha una dona fatal com a personatge secundari. En el film, una jove de bona posició escriu una carta a Jacob de Larn, amb motiu del matrimoni que aquest es disposa a contraure. La missiva diu com segueix: "Un caballero no se puede casar con la hija de una pecadora". Aquesta carta, i d'altres que ens relaten el passat llibertí de la mare de Marta, portarà l'enamorada de Jacob a perdre la salut, i requerirà per part de la mare d'aquesta un reconeixement de

9 De Magí Murià i Fructuós Gelabert, de l'any 1915.

10 Basat en el drama passional Amor que mata, de José Vives. 
la veritat. La senyora Vélez, la mare, al final del film, reconeix: "Es verdad, perdóneme. Es el castigo por mi pecado". Aquestes paraules fan que la poca vida que li queda a la filla es perdi. Mentrestant, el personatge que ha planificat tot això és també a la casa. Es tracta de la jove autora dels anònims que no ha volgut perdre's el desenllaç dels esdeveniments per, d'aquesta manera, disfrutar més de la seva venjança. La gelosia de l'amor de Marta i Jacob fan que la jove rebutjada planifiqui i manipuli els sentiments per tal d'aconseguir el seu propòsit, que no és altre que trencar el compromís de la parella. D’altra banda, el director del film realitza un canvi d'ubicació del melodrama, que passa de desenvolupar-se del medi rural a la ciutat, en refinats ambients burgesos, amb una posada en escena moderna i cosmopolita, que ens permet descobrir els interiors de les cases catalanes de la burgesia de l'època. L'argument, tot i tenir la força en l'incident desencadenant, que és la carta que rep l'aristòcrata, focalitza el seu esforç en la realització d'un fulletí passional de temàtica social, on els preceptes morals determinen la trama, fortament carregada d'emotivitat. El mateix any 1911, Segundo de Chomón realitza La hija del guardacostas, basada en un conte català del segle XVIII (González, 1987:108-109). En el film, María Moreno interpreta la filla del guardacostes, una jove que viu amb el seu pare en un petit poble de la costa. La filla té un promès pescador que feineja amb el seu pare. Aprofitant la partida dels pescadors, el marquès, que està prendat de la bellesa de la jove, la convida aquella nit a casa seva i aprofita per fer-li la cort. Després de força insistència, el marquès convenç la jove que marxi amb ell, amb la promesa d'una vida plena de benestar econòmic i estatus social. El pare i l'enamorat van a buscar la noia a casa del marquès i la troben vestida elegantment i enmig d'una festa. Els dos homes discuteixen amb la jove que, penedida, demana perdó al seu pare, que la rebutja. Al final, la jove es suïcida llançant-se al mar. Amb lligams internacionals posteriors, Ricardo de Baños, Vicente Blasco Ibáñez i Max André roden Sangre y arena l'any 1917, basat en la novel.la homònima de Vicente Blasco lbáñez de l'any 1908. En aquest cas, la dona fatal se'ns presenta poderosa econòmicament. És Doña Sol, una rica, vídua i sofisticada marquesa, que s'interposa en el matrimoni de Carmencita i Juan Gallardo, una clàssica parella que han crescut junts i s'han acabat casant. Doña Sol és una dona capritxosa i fa del torero una eina per a la seva distracció, absorvint-lo fins a tal punt que l'home s'oblida que té una muller. En una corrida rep una cornada i, al llit de mort, es reconcilia amb la seva dona. El film també s'estrena a París, i obté un ressò força important, fins al punt de fer-se'n tres adaptacions els anys 1922, 1941 i 1989, coincidint curiosament amb unes actrius que ja interpreten el personatge en altres produccions en la seva carrera cinematogràfica. Parlem d' actrius del talent de Nita Naldi, Rita Hayworth i Sharon Stone ${ }^{11}$, respectivament.

Com a personatge de dona fatal, però essent-ho degut al fet que és víctima del context i situació social en què viu, ens trobem amb diverses produccions que ens podem ajudar a definir el tipus. L'any 1908, Enrique Giménez i Fructuós Gelabert estrenen La Dolores'², un film que té com a eix central la figura femenina de Dolores. La noia, enamorada de Melchor, és sorpresa pel seu pare en actitud qüestionable amb Melchor. El pare la maltracta i, fruit d'això, mor d'un atac de cor. La Dolores va a buscar Melchor per consolar-se i només en rep

11 Nita Naldi interpreta Doña Sol en la pel.lícula dirigida per Fred Niblo I'any 1922; Rita Hayworth interpreta Doña Sol en el film dirigit per Rouben Mamoulian; Sharon Stone fa el paper de Doña Sol a la producció dirigida per Javier Eliorreta l'any 1989.

12 E. Giménez i F. Gelabert, 1908 i estrenada a Madrid el 1911, basada en una adaptació de José Feliú i Codina i el mestre Tomás Bretón, de l'obra La Dolores, 1892. 
menyspreu. Ella marxa del poble i treballa en un mesón. Allà també té molts pretendents, i Melchor reapareix en la trama volent recuperar la seva estimada. Ella el desatén i permet que d'altres pretendents li facin la cort. Melchor, dolgut, canta amb els seus amics una copla plena d'insults per a la Dolores. Lázaro surt en defensa de la seva estimada i repta a duel Melchor. En la pugna, Lázaro mata el seu oponent. La Dolores, per defensar el que és ara el seu estimat, i qui li ha demostrat el seu amor veritable i el seu respecte, es declara autora del crim. Però Lázaro confessa i és detingut. L'actriu que interpreta la Dolores és Mercedes Marsal. En un altre context, l'any 1914, Adrià Gual realitza Misterio de dolor, a partir de la seva pròpia peça teatral de l'any 1904 (Ruiz, 2000: 139-140). Té lloc als Pirineus catalans, on una vídua de nom Mariana i la seva filla, Marianeta, coneixen un pastor, Silvestre, i de seguida comencen les competències entre mare i filla. És curiós com el nom de mare i filla serveix d'antecedent a la trama que seguirà l'ordre jeràrquic pel que fa a la relació amb Silvestre. D'entrada serà Mariana qui tindrà una relació amb Silvestre però, degut a un accident del pastor, aquest coneix Marianeta i esclata entre ells una gran passió. Tot i que Marianeta sap de la relació i dels sentiments de la seva mare, no pot evitar l'atracció que sent per Silvestre. El drama acaba amb el suïcidi de la mare i la culpabilitat del pastor per la resta dels seus dies. Segons argumenta Ruiz: "la tragedia que refiere la película cobra mayor dimensión al sustentarse en la incertidumbre de la pareja de amantes de si el drama es consecuencia de que su acción ha sido descubierta. Aunque nunca podrán salir de dudas, el tiempo no borrará jamás la cada vez más certera sospecha del silencioso sacrificio, el acto de contención que ha suspuesto el suicidio de la viuda." L'actriu que s'interposa entre el pastor i la mare és Emilia Baró. D'altra banda, Sol y sombra, sorprenentment per l'època, va estar dirigida per Musidora — també l'actriu principal_, Jacques Lasseyne i José Sobrado de Onega l'any 1922, éssent una coproducció francoespanyola estrenada a París i a Madrid. L'actriu interpreta una jove enamorada andalusa, d'aparença gitana i morena, i, alhora, la seva antagonista, una estrangera d'aparença nòrdica i rossa que pretén seduir el seu estimat. Davant de la impotència que això crea en la protagonista, el film, de manera molt personal i detallista, descriu l'angoixa de l'ànima de la protagonista que, després de veure com el seu estimat és batut per un toro, i fruit de la ràbia que sent per l'estrangera, la mata. El destí de la dona fatal és l'ingrés en un convent, donant a entendre que Juana és fatal degut a les circumstàncies. Per acabar, el llavors actor Florián Rey s'estrena com a realitzador amb La revoltosa'13 I'any 1925. Mari-Pepa és victima de la gelosia degut a les llicències de Felipe. Degut a això, i per venjarse'n, coqueteja amb tots els marits del pati. Aquest fet indigna Felipe i el porta a començar enfrontaments amb tots els marits. Darrera dels fets hi ha Gorgonia, que ha planificat una venjança en contra de Mari-Pepa, citant tots els marits a casa de la jove a la mateixa hora. L'enrenou finalment és solventat, i Felipe i Mari-Pepa es reconcilien. Josefina Tapias és La Revoltosa, que, víctima de les circumstàncies, reacciona de manera fatal, sense arribar a ser tràgica. Florián Rey resol el conflicte de manera positiva i restaura la pau perduda.

Com a personatge de dona fatal, però sense ser jove ni seductora, ja dins del cinema mut espanyol, trobem alguns títols que fan palesa l'existència d'aquesta imatge arquetípica. Un dels primers casos és La casa de la Troya ${ }^{14}$. En el film, Lola Valero interpreta la Maragota, tia política de Carmen, la protagonista. Maragota posa en pràctica un pla pèrfid amb la idea de forçar la seva fillastra a casar-se amb el seu fill Octavio, degut a la recent mort del pare de

13 Film basat en la sarsuela La revoltosa (1897) de José López Silva, Carlos Fernández Shaw i Ruperto Chapí.

14 Alejandro Pérez Lugín y Manuel Noriega (assessor), 1925. 
Carmen, que I'ha deixat com a única i rica hereva. Finalment, i després de molts entrebancs entre la protagonista i Gerardo, el seu estimat, degut a les trampes de la seva tia, Carmen descobreix es malèfics plans de Maragota i aconsegueix deslliurar-se de la seva nefasta influència i recuperar la relació amb Gerardo.

Pel que fa a la fesomia de les actrius de les quals hem estat parlant fins ara, i tenint en compte que cronològicament s'adscriuen a un període del cinema precís, podem parlar d'unes actrius amb els trets comuns següents: morenes, cabells ondulats i foscos, llavis molsosos i ulls grossos, de pell blanca però discretament maquillades. Molt enjoiades però sense ser opulentes, amb escots discrets però alhora reveladors, presumides i alhora discretes, amb una tendència natural a la contradicció, com el "fer" del personatge que interpreten. Com a títols que podrien ser reveladors o si més no indicadors de possibles trames amb dones fatals, podríem parlar de La tempranica; Carmen; La gitanilla; Pasionaria; Miss Ledya; La bruja; Maruxa; La sinventura; Lolita, la huérfana; Edurne, modista bilbaína; Flor de espino; Carmiña, flor de Galícia; La chica del gato; La malcasada; Frivolinas; Rosa de Madrid; La loca de la casa; Corazones sin rumbo; Rocío de Albaicín, i Esencia de verbena. Podria ser més per motius publicitaris que no pas per les trames, que no mostren signes de contenir una dona fatal. Tot i així, podem parlar dels reclams falsos pel títol, um engany publicitari que no fa cap favor al personatge de la dona fatal inicialment però que, a llarg termini, crea certa ansietat en el públic, que cerca aquesta figura en les trames dels films que va a veure al cinema. Pel que fa al cartellisme, també podem parlar de certa incitació a continguts de dona fatal que després no són en les trames d'aquests films, que més aviat mostren dones supèrflues, dèbils i fins i tot sense un rol definit en el film. Algunes d'aquestes pel.lícules són, per exemple, Pasionaria, El sello de oro/Fanatismo de una secta, Los arlequines de seda y oro, Gloria que mata, iiGranero!!, La sinventura, La bejarana, El negro que tenía el alma blanca, Frivolinas, La terrible lección i Corazones sin Rumbo.

\section{BIBLIOGRAFÍA CITADA}

AGUILAR, Carlos; GENOVER, Jaume. Las estrellas de nuestro cine, Madrid: Alianza, 1996.

AZZOPARDI, Michel. Le temps des vamps: $1915-1965$ (cinquante ans de sex-appeal), Paris: L'Harmattan, 1997.

BARREIRA, Domingo F.: Biografía de Florián Rey, Madrid: ASDREC, 1968.

BARREIRO, Javier. Raquel Meller y su tiempo, Zaragoza, D.G.A., 1992.

CABERO, Juan Antonio. Historia de la cinematografía española (1896-1948), Madrid: Gráficas Cinema, 1949.

CAPARRÓS, José Ma . Historia crítica del Cine español (Desde 1897 hasta hoy), Barcelona: Ariel, 1999.

GILI, Jean A. Le cinéma italien, Paris: La Martinière, 1996.

GONZÁLEZ, Palmira. Història del cinema a Catalunya. L'època del cinema mut (1896-1931), Barcelona, Els llibres de la Frontera,1986.

- Els anys daurats del cinema clàssic a Barcelona (1906-1923), Barcelona: Institut del Teatre, 1987.

- El cinema mut, Barcelona: UOC, 2006.

- y CÁNOVAS BELCHI, Joaquín T. Catálogo del cine español. Películas de ficción. 19211930. Volumen F2, Madrid: Filmoteca Española, 1993. 
GUBERN, Román, "Y la luz se hizo sexo", Nosferatu, 2, 1990.

LARRAZ, Emmanuel: Le Cinéma espagnol des origines à nos jours, París: Mason et Cíe, 1973.

MARTíNEZ TORRES, Augusto (ed.): Cine Español 1896-1983, Madrid: M. de Cultura, 1989.

MÉRIMÉE, Prosper. Carmen, Barcelona: Bruguera, 1981.

MINGUET, Joan M. Paisaje(s) del cine mudo en España, Valencia: Fimoteca (IVAC), 2008.

PÉREZ PERUCHA, Julio. (ed.) Antología crítica del cine español 1906-1995, Madrid: Cátedra/ Filmoteca Española, 1997.

PORTER MOIX, Miquel. Història del cinema a Catalunya, Barcelona: Generalitat de Catalunya, 1992.

POZO, Santiago. La industria del cine en España (1896-1970), Barcelona: Universitat de Barcelona, 1984.

REY, Antonia del. El cine español de los años veinte. Una identidad negada, Valencia: Eutopías / Episteme, 1998.

RIAMBAU, E. El paisatge abans de la batalla. El cinema a Catalunya 1896-1939, Barcelona: Libres de l'índex, 1994.

ROMERO, V.; MARTÍNEZ, J.; AMOR, M. Cine mudo español, un primer acercamiento de investigación, Madrid: UCM, 1991.

RUIZ, Luis Enrique. Obras pioneras del cine mudo. Orígenes y primeros pasos (1895-1917), Bilbao: Mensajero, 2000.

RUIZ, Luis Enrique. El cine mudo en sus películas, Bilbao: Mensajero, 2004.

SÁNCHEZ SALAS, Daniel. Historias de luz y papel. El cine español de los años veinte a través de sus adaptaciones de narrativa literaria española, Murcia: Filmoteca Regional, 2007. 